\title{
EM QUE CONSISTE A ENFERMAGEM
}

\section{Emllia Luigia Saporiti Angerami* Francisco de Assis Correia**}

ANGERAMI, E.L.S. \& CORREIA, F. de A. Em que consiste a enfermagem. Rev. Esc. Enf. USP, São Paulo, 23(3):337-344, dez. 1989.

Nesse trabalho, partimos do significado de Enfermagem à luz da etimologia. A seguir, fazemos um rastreamento historico da Enfermagem, detectando as principais oticas, que ao longo da história iluminaram o seu exerctcio. Por fim, abordamos a noção de Enfermagem à luz de seu pluralismo.

UNITERMOS: Enfermagem. Enfermagem como profissão.

\section{INTRODUÇÃO}

Definir a Enfermagem é uma tarefa difícil, quer pela restrição ou limitação que toda definição implica, quer pela dificuldade de encontrar uma expressão breve e completa significante do vocábulo.

Há, entretanto, uma forma de definir um conceito que parte da etimologia; o rastreamento semântico permite-nos ver a origem da palavra, mas não nos indica toda a sua dimensão. Muitas vezes, o que explica o significado de um termo é o seu uso. No que tange à Enfermagem, esse termo historicamente sempre significou essencialmente cuidado dos enfermos, mas a sua ótica é que se modifica ao longo dos séculos e, ultimamente, foi enriquecido pelas novas teorias, a ponto de hoje existir um pluralismo de concepções de Enfermagem.

Nesse nosso trabalho, partimos do significado de Enfermagem à luz da etimologia (1). A seguir, fazemos um rastreamento histórico da Enfermagem, detectando as principais óticas, que ao longo da história iluminaram o seu exercício (2). Por fim, abordamos a noção de Enfermagem à luz de seu pluralismo (3).

* Professor Titular e Diretora da Escola de Enfermagem de Ribeirão Preto da Universidade de São Paulo.

** Professor Assistente, responsável pelas disciplinas de História e Legislação da Enfermagem e Ética do Departamento de Enfermagem Psiquiátrica e Ciências Humanas da Escola de Enfermagem de Ribeirão Preto da Universidade de Sẫo Paulo. 


\section{ENFERMAGEM À LUZ DA ETIMOLOGIA}

Segundo a etimologia, Enfermagem quer dizer ato ou efeito de tratar os enfermos. Enfermo é palavra derivada do latim infirmus, ou seja, doente, doentio, fraco, débil, achacoso, imperfeito (CUNHA ${ }^{2}$, FONTINHA ${ }^{4}$ ).

\section{RASTREAMENTO HISTÓRICO}

A enfermagem nasceu das necessidades humanas em relação aos cuidados de saúde. Por isso, é atividade tão antiga quanto o homem, visto que responder aos seus anelos de saúde, de tratamento em suas enfermidades é parte integrante do processo de hominação. O sofrimento não só levou o homem a pensar sobre sua vida, mas, também, a encontrar forma de superá-lo.

2.1. A enfermagem nas comunidades primitivas: nas comunidades primitivas delineia-se o cuidado de enfermagem enquanto tratamento por tentativa, de maneira empírica, sobretudo no que tange a doenças externas e recurso à magia, ao sobrenatural no que respeita às doenças internas. A doença, o sofrimento, os males são entidades que devem ser exorcizadas. Sacerdotes-médicos-enfermeiros são profissionais desse exorcismo. Por isso, templo e hospital confundem-se numa mesma tarefa inseparável. Relações mitológicas estabelecem-se entre doenças e deuses. Vigilância e advinhação fazem parte de um mesmo processo. Enfermagem, aqui, é arte de saber manipular as forças da natureza e das divindades para a saúde do homem e das comunidades.

A enfermeira era aquela pessoa que intuitivamente criava um ambiente confortável para o cuidado e a segurança do doente. Estes cuidados tinham como elementos básicos o carinho, a limpeza, o conforto, alimentação e procedimentos simples de cuidado ao doente.

2.2.A enfermagem entre as civilizações antigas: com a evolução das grandes culturas, desenvolve-se igualmente o cuidado para com a saúde. Reis-sacerdotes-mágicos-enfermeiros são os intermediários entre as divindades e os homens e os mediadores da saúde. Os templos-hospitais ampliam-se e dão lugar não só a um número maior de enfermos, mas também oferecem banhos, dietas, inalações, sangrias, poçōes mágicas, "incubadoras", cuidados de enfermagem os mais diversos - sendo que na Índia exige-se dos enfermeiros "conhecimento da preparação das drogas, inteligência, devoção ao paciente e pureza do corpo e alma". A Enfermagem faz parte de um mesmo universo regido por forças sobrenaturais.

2.3. A enfermagem a partir de Hipócrates: com Hipócrates (mais ou menos 460 ou $459 \mathrm{AC}$ ), a medicina dissocia-se das superstições e misticismos e inicia seu período de diagnóstico e tratamento, atenção aos sintomas e cura entendida como propiciar condiçōes de o homem readquirir seu equilíbrio. Sem especificar o en- 
fermeiro, há referência a um colaborador do médico que executa as tarefas por ele determinadas. Neste momento, pode-se dizer que, a enfermeira passa a cumprir as ordens do médico.

2.4. A enfermagem no período cristão e medieval: com a introdução da medicina científica, na antiga Roma, os cuidados com os doentes se modificaram ocorrendo um certo acompanhamento por parte da Enfermagem. Fundamentalmente neste período muda a ótica do cuidado do doente. Já nāo é por magia ou superstição que se cuida dos doentes: é por amor ao próximo, por obra de misericórdia. Vê-se no enfermo a imagem do próprio Cristo enfermo e que necessita dos cuidados urgentes dos cristãos. O motivo deste cuidado é alcançar o Reino de Deus, a vida eterna. E Enfermagem é vista como atividade caritativa, quer nos mosteiros, nos conventos, nos hospitais, quer no atendimento domiciliar. O modelo que se tem é o do bom samaritano (Lc 10, 29-37), que cuida do doente até o seu pleno restabelecimento. Por isso, enfermagem é atividade fraterna - cuidar do irmão doente - e aqueles que desempenham estes trabalhos são chamados irmãos ou irmãs, nome que será mudado, tardiamente, no século XVIII, na Inglaterra, de "Sister" para "Nurse" (NUTTING \& DOCK5).

É neste período que surgem as Diaconizas, as quais eram ordenadas para o serviço, o qual consistia em atender as necessidades de sobrevivência das pessoas carentes e doentes: dar água, alimento, vestimenta sempre permeado do ideal de serviço e do amor ao próximo. Os mesmos princípios nortearam as "Damas romanas" as quais se dedicaram a fundar hospitais para atender doentes graves e vítimas de epidemias. Estas damas dedicavam-se também ao ensino.

Em geral os historiadores concordam que a prática médica na Idade Média era quase na sua totalidade exercida pelas ordens monásticas.

Atentamos para algumas características daquela época em relação a recepção e cuidados prestados.

A Infirmary (enfermeira) presidida pelo Infirmarius situada na cláusula era destinada aos membros da ordem. O Hospice dirigido pelo hospitalarius atendia pessoas da comunidade e pacientes em geral. A assistência era prestada pelas monjas aos pacientes de sexo feminino e pelos monges aos pacientes de sexo masculino.

Sua prática consistia em manter o doente aquecido colocando tijolos quentes, realizar friç̧ōes, limpar o chão e servir alimentos.

Das outras organizaçōes que surgiram para cuidado dos doentes destacamos no tempo das Cruzadas especificamente os "Cavaleiros de São João de Jerusalém" por terem conseguido mudar velhos regulamentos hospitalares, mas especificamente, pela condução e divisão do trabalho que apresentavam. A dedicação ao preparo do ambiente, a hierarquização das funções e a detalhada especificação de atividades, nos remetem às raízes da atual atividade de administração hospitalar. 
O "Grande mestre" da ordem era o superior ou chefe oficial da enfermaria, ele presidia e zelava pelo bem estar. $\mathrm{O}$ Infirmarian, cavaleiro profissional, assistido por dois cavaleiros chamados Prodomi, vivia no prédio, era responsável pela direção geral e manutenção do hospital. Cabia a ele, além de manter a disciplina e boa conduta dos oficiais, cuidar do bem estar dos doentes, a tal ponto que era obrigado a supervisionar o trabalho médico e a execução das ordens pelos auxiliares.

O regulamento determinava as funções específicas do Infirmarius, dos Prodomi e dos demais oficiais (NUTTING \& DOCK ${ }^{5}$ ).

2.5. A enfermagem na Idade Moderna: a ótica da Enfermagem moderna cindiu-se com a concomitante cisão do mundo moderno: de um lado, constata-se a permanência da Enfermagem à luz da caridade cristã e, de outro, a enfermagem exercida à luz da secularização e da autonomia; aquela, ainda permanecia acesa pela chama da caridade, da vocação religiosa, do encontro pessoal; essa, pouco a pouco vai evoluindo pela profissionalização, pela humanização ou filantropia e pelo vínculo contratual como qualquer profissão emergente. Em ambas, porém, predomina até a primeira metade do século XIX, o pragmatismo, com sinais de evolução para uma prática mais elaborada desse saber.

Só na segunda metade do século XIX, entretanto, com Florence Nightingale, a Enfermagem assume a modernidade no sentido de racionalizar a prática, conferindo-lhe atividade noética, metódica e crítica.

$\mathrm{O}$ discurso, que então aparece, pretende ser a interpretação teórica de uma prática, tão antiga quanto os homens.

De prático e intuitivo ao longo dos séculos, o exercício da Enfermagem passou a elaborar o seu questionamento, a sua reflexão, a sua investigação e a sua pesquisa.

A situação dos hospitais encontrada por Florence Nightingale era de pouca ou nenhuma condição higiênica, cirurgias realizadas sem anestesia, lixo em todos os ambientes e pessoas de baixo nível moral assistindo aos enfermos.

Em sua nova proposta para a enfermagem a descreve como uma prática cujo foco é o ambiente do paciente e este deve estar nas melhores condiçōes para a natureza agir. As áreas por ela ressaltadas foram: ventilação, luz, temperatura e controle de odores e gases.

2.6. A enfermagem contemporânea: como no passado, também agora, mas de modo mais rápido e intenso, diversos fatores são responsáveis pelas distintas concepçōes de Enfermagem:

- as transformações sócio-econômico-culturais e políticas e suas repercussões na vida do homem, de seu ecossistema, de seu universo; 
- o desenvolvimento das ciências básicas-biológicas, humanas, exatas e os avanços tecnológicos;

- as tendências filosóficas;

- as próprias pesquisas na área de Enfermagem;

- as novas dimensōes da educação;

- as tendências das políticas de saúde.

Esses e outros fatores contribuem sobremaneira para nova evolução da Enfermagem.

Até a emergência da enfermagem como ciência no início da década de 50, a prática profissional era baseada em regras, princípios e tradições que foram passando ao longo do tempo através do ensino formal e informal. Os princípios que orientavam a prática e que lhe atribuiam um caráter científico, eram proposições existentes nas ciências físicas e biológicas transferidas para a enfermagem.

A enfermagem desta etapa construiu um conhecimento intuitivo sobre as necessidades de saúde das pessoas e o aplicou na sua prática de cuidar dos doentes, mas este conhecimento intuitivo mostrou-se insuficiente, desestruturado e inviável.

$\mathrm{Na}$ década de 50 iniciaram-se sérios esforços na busca de um conteúdo cognitivo próprio, na formulação de alguns conceitos bem como no aperfeiçoamento de enunciados existentes. Nesta fase são relevantes as publicaçōes de Ida Orlando, Virgínia Henderson, Hildegard Peplau.

Nas décadas 60-70 há um forte impulso na sistematização do conhecimento, formulação de conceitos, teorias e da terminologia, dando passos para sua própria epistemologia. Estas teorias procuram delimitar o objeto, área de pertinência. Freqüentemente a enfermagem foi representada como uma disciplina com enfoque na interação entre o enfermeiro e o cliente. São desta época os estudos de Lidia Hall (1966); Myra Levine (1967); Martha Rogers (1970); Dorothea Orem (1971); Imogenes King (1971); Sister Callesta Roy (1976) (FAWCETT ${ }^{3}$ ).

A fase que vivenciamos é a do reconhecimento da enfermagem como ciência, passando "do factual para o conceitual".

As teoristas tem revelado, em suas publicações, mudanças e progressos em relação às suas proposições iniciais, demonstrando cristalização de suas idéias bem como a influência de uma sobre a outra (CHIM \& JACOBS ${ }^{1}$, FAWCETT ${ }^{3}$ ). Outro aspecto que revela a consolidação deste conhecimento é o crescente uso na pesquisa, no ensino e algumas tentativas de aplicação na prática. 


\section{PLURALISMO DA ENFERMAGEM}

Este breve rastreamento histórico mostrou-nos a evolução da Enfermagem que, de prática espontânea, pragmática, intuitiva, caritativa... evoluiu para profissão, saber, arte, ciência...

O resultado atual mostra-nos, porém, nāo uma única concepção de Enfermagem, mas um pluralismo de concepçōes. Num mundo pluralista como o nosso, também a Enfermagem traduz-se em pluralidade de conceitos, de modelos, de tendências filosóficas, de objetos, de processos...

Este pluralismo da Enfermagem faz parte daquilo que é constitutivo do homem. Faz parte do contexto de sua própria existência que é composta de realidades bastante diversas e que a experiência vivida pelo próprio homem demonstra não poder provir senão de muitas fontes originalmente distintas. Daí a dificuldade de o homem reduzir esta multiplicidade a um denominador comum, em teoria como na prática.

Por outro lado, este pluralismo da Enfermagem é, também, resultado da cultura atual, onde já não existe mais um monolitismo explicador, mas várias possíveis explicações das realidades. Assim, já não há uma filosofia, mas várias filosofias; não há uma cultura, mas várias culturas; não há um centro de saber, mas vários centros de saber; já não há, também, uma Enfermagem, mas várias Enfermagens...

Falar, pois, em pluralismo da Enfermagem, é afirmar a existência de uma multiplicidade e de uma diversidade de Enfermagem, de modelos, de tendências...

Assim entendido o pluralismo, constatamos o seguinte quadro no que diz respeito à Enfermagem:

3.1. Pluralismo de definições de Enfermagem enquanto profissão:

- ela é arte

- ela é arte e ciência

- ela é ciência aplicada

- ela é técnica

- ela é profissão liberal

- ela é ideal

- ela é prática assistencial

- ela é agenciadora de mudança social e cultural

- ela é prática social...

Ao afirmarmos que a definição de Enfermagem é plural, não queremos, contudo, dizer que esses conceitos sejam opostos ou irreconciliáveis. Pretendemos, sim, expressar que, por trás deles há sempre uma perspectiva diversa. Ora se privilegia um, ora outro, dependendo do tipo de opção que o pesquisador ou o profissional tem, frente à profissão e à sua prática. 
3.2. Pluralismo de Recipientes da Enfermagem (recipient of nursing care)

- o homem

- o indivíduo

- a família

- a comunidade

- o país

- o continente...

3.3. Pluralismo de filosofias na Enfermagem:

- empirismo lógico

- abordagem historicista

- abordagem fenomenológica

- abordagem existencialista

- abordagem dialética

- abordagem materialista histórica

- abordagem holístico-humanista

- abordagem funcionalista

- abordagem histórico-estrutural...

3.4. Pluralismo de modelos de Enfermagem:

Cada conceito de Enfermagem tem, todavia, um modelo que o embasa e esses, hoje, podem ser:

- modelo comportamental de Johnson

- modelo de sistemas abertos de King

- modelo de conservação de Newman

- modelo de auto-cuidado de Orem

- modelo de processo vital de Rogers

- modelo de adaptação de Roy...

3.5. Pluralismo de processo de Enfermagem:

- promover e manter o equilíbrio orgânico

- diagnosticar as necessidades do cliente

- prescrever os cuidados

- interação terapêutica entre enfermeira-cliente

- avaliar as respostas do indivíduo ao tratamento recebido

- conservação das energias do paciente e do universo

- facilitar as trocas de energia entre o homem e a natureza

- ajudar a pessoa a se adaptar aos estímulos do ambiente interno e externo

- promover meios para atender às necessidades do cliente e do ambiente

- promover a adaptação e a integração da pessoa em vista de sua saúde

- identificar problemas

- diagnosticar o comportamento das pessoas

- determinar os objetivos da assistência... 


\section{CONCLUSĀO}

Se optamos por dizer que a Enfermagem consiste, hoje, em ser pluralista, no sentido anteriormente exposto, a título de conclusão, precisamos o seguinte:

- o pluralismo na Enfermagem, como em outras áreas, representa uma tentativa de superar a uniformidade do passado;

- se não houver a aceitação deste pluralismo, a própria Enfermagem se fecha e não progride;

- este pluralismo supõe variedade de correntes e de opçōes teóricas e práticas;

- este pluralismo é resultante não apenas do momento cultural, mas de uma série de fatores e de condicionamentos: de classe, de nação, de raça, de sexo...

Mas, para nós, no momento atual de Brasil, interessa-nos progredir sobretudo para uma Enfermagem que responda às nossas necessidades de saúde. A Enfermagem deve ser para nós, também, mediação de transformação, para melhoria da vida de todos os brasileiros, através do cuidado de pessoas. Essa tem sido a característica fundamental da profissão desde o seu início e atualmente permeia todos os modelos teóricos existentes.

ANGERAMI, E.L.S. \& CORREITA, F. de A. What does nursing consist of. Rev. Esc. Enf. USP, São Paulo, 23(3):337-344, Dec. 1989.

In the present study we started of the meaning of Nursing from etymological viewpoint. We then made an historical survey of Nursing, detecting the main guiding concepts that directed its practice throughout history. We finally approached the notion of Nursing in the light of its plurality.

UNITERMS: Nursing. Nursing profession.

\section{REFERÊNCIAS BIBLIOGRÁFICAS}

1 CHINN, P.L. \& JACOBS, M.K. Theory and nursing: a systematic approach. St. Louis, Mosby, 1983. $221 \mathrm{p}$.

2 CUNHA, A.G. da Dicionário etimológico nova fronteira da lingua portuguesa. Rio de Janeiro, Nova Fronteira, 1982.

3 FAWCETT, J. Analysis and evaluation of conceptual models of nursing. Philadelphia, Davis, 1984. $307 \mathrm{p}$.

4 FOnTINHA, $R$. Novo dicionário etimológico da língua portuguesa. Porto, Editorial Domingos Barreira, s.d.

5 NUTTING, M.A.\& DOCK, L.L. A history of nursing. 11. ed. New York, Putnam's, 1935, 2 v. BIBLIOGRAFIA

1 ALMEIDA, M.C.P. de \& ROCHA, J.S.Y. O Saber de enfermagem e sua dimensão prática. São Paulo, Cortez, $1986.128 \mathrm{p}$.

2 DOLAN, J.A. Nursing in society: a historical perspective. 14. ed. Philadelphia, Saunders, 1978. $402 \mathrm{p}$.

3 GEORGE, J.B. Nursing theories: the base for professional nursing practice. New Jersey, Prentice-Hall, $1980.230 \mathrm{p}$.

4 PAIXÃO, W. História da enfermagem. 5. ed. Rio de Janeiro, Júlio C. Reis, 1979, 141 p.

Recebido em 22/11/88 